\title{
Management of Symmetrical Peripheral Gangrene
}

\author{
Agus Iwan Foead, Amuthaganesh Mathialagan', Raghu Varadarajan², Michael Larvin² \\ Departments of Orthopedics, ${ }^{1}$ Pharmacology and ${ }^{2}$ Surgery, School of Medicine, Perdana University-Royal College of Surgeons Ireland Selangor, Malaysia
}

\section{Abstract}

Symmetrical peripheral gangrene (SPG) is a rare, debilitating disease that deserves more widespread concern among the medical fraternities. The objective of this review is to outline the etiology, pathology findings, and management practices of SPG. About $18 \%-40 \%$ mortality rate was reported, and survivors have high frequency of multiple limb amputations. SPG is the hallmark of disseminated intravascular coagulation (DIC). The main pathogenesis theory, to date, is microthrombosis associated with disturbed procoagulant-anticoagulant balance. The treatment of SPG is largely anecdotal and theoretically involves heparin-based anticoagulation and substitution of natural anticoagulants. Early recognition, prompt management of DIC, and underlying conditions may halt the progression of the disease. The multicenter randomized controlled trial should be set up to formulate the proper treatment guidelines.

Keywords: Disseminated intravascular coagulation, microthrombosis, procoagulant-anticoagulant balance, purpura fulminans, symmetrical peripheral gangrene

\section{INTRODUCTION}

Symmetrical peripheral gangrene (SPG) is a rare complication in the intensive care unit. Its definition involves symmetrical ischemic damage, which occurs at the distal part of the limbs or genitalia, in the absence of a major vascular occlusive disease. It has high risk of mortality and high frequency of multiple limbs amputation in those who survive. ${ }^{[1]}$ SPG should be suspected at the first sign of marked coldness, pallor, cyanosis, or pain in an extremity as the condition can progress rapidly to acrocyanosis and if not reversed frank gangrene. SPG is also sometimes referred to as purpura fulminans $(\mathrm{PF}) . \mathrm{PF}$ is an acute thrombotic disorder which manifests as blood spots, bruising, and discoloration of the skin. It results from coagulation in small blood vessels within the skin and rapidly leads to skin necrosis and disseminated intravascular coagulation (DIC). ${ }^{[2]} \mathrm{PF}$ is rare and most commonly occurs in babies and small children although it can also occur in adults with severe sepsis. Its presence is almost always a marker of DIC. ${ }^{[3]}$ In Warkentin's review, both are of the same pathologic condition, i.e., microthrombosis, and both are of the same spectrum of manifestations. When there is additional or predominant nonacral tissue necrosis, the term PF is applicable. Otherwise, it is defined as SPG for clinical investigations. ${ }^{[4]}$

\begin{tabular}{|l|l|}
\hline \multicolumn{3}{|c|}{ Access this article online } \\
\hline Quick Response Code: & Website: \\
& www.ijccm.org \\
\hline
\end{tabular}

\section{ETIOLOGY}

The etiology of SPG is multifactorial; however, in general, it has been divided into two main categories which are infective factors and noninfective factors. ${ }^{[5-9]}$ Infective etiology of SPG is as follows: Pneumococcus, ${ }^{[10,11]}$ Staphylococcus aureus, ${ }^{[10,12]}$ Neisseria meningitidis, ${ }^{[7,12]}$ Streptococcus pyogenes,${ }^{[10]}$ Klebsiella pneumoniae, Escherichia coli, Salmonella paratyphi, Proteus vulgaris, Proteus mirabilis, Pasteurella multocida, ${ }^{[13]}$ Pseudomonas, ${ }^{[10,12]}$ Enterococcus faecalis,${ }^{[14]}$ Capnocytophaga canimorsus (DF2), ${ }^{[15]}$ Plasmodium falciparum, ${ }^{[16]}$ Mycobacterium tuberculosis, ${ }^{[17]}$ Rubeola, Varicella zoster,${ }^{[13,18]}$ dengue, ${ }^{[19]}$ and human immunodeficiency virus. ${ }^{[20]}$ Noninfective etiology of SPG refers to conditions that precipitate SPG occurrence such as myocardial infarction, ${ }^{[13]}$ cardiac failure, ${ }^{[13,18]}$ hypovolemic shock, ${ }^{[18]}$ hypertension, ${ }^{[18]}$ pulmonary embolism, ${ }^{[13]}$ supraventricular tachycardia, ${ }^{[21]}$ Hodgkin's lymphoma, ${ }^{[22]}$ lung adenocarcinoma, ${ }^{[23]}$ adenocarcinoma-associated thrombotic

Address for correspondence: Dr. Agus Iwan Foead, School of Medicine, Perdana University-Royal College of Surgeons in Ireland, Block D1, MAEPS Building, MARDI Complex, Jalan MAEPS Perdana, 43400 Serdang, Selangor, Malaysia. E-mail: agus.iwan@perdanauniversity.edu.my

This is an open access journal, and articles are distributed under the terms of the Creative Commons Attribution-NonCommercial-ShareAlike 4.0 License, which allows others to remix, tweak, and build upon the work non-commercially, as long as appropriate credit is given and the new creations are licensed under the identical terms.

For reprints contact: reprints@medknow.com

How to cite this article: Foead AI, Mathialagan A, Varadarajan R, Larvin M. Management of symmetrical peripheral gangrene. Indian J Crit Care Med 2018;22:870-4. 
endocarditis, ${ }^{[24]}$ systemic lupus erythematosus, ${ }^{[25]}$ polymyalgia rheumatica, ${ }^{[22]}$ antiphospholipid syndrome, ${ }^{[26]}$ congenital and acquired protein $\mathrm{C}$ and $\mathrm{S}$ deficiencies, ${ }^{[27]}$ sickle cell disease, ${ }^{[28]}$ cryoglobulinemia, ${ }^{[28]}$ and idiopathic. ${ }^{[27]}$ SPG can also be caused by drugs such as dopamine, ${ }^{[29]}$ noradrenaline, ${ }^{[30]}$ adrenaline, ${ }^{[31]}$ warfarin, ${ }^{[23,24]}$ and propylthiouracil. ${ }^{[32-34]}$ A summary of the etiological factors is shown in Table 1.

\section{Theories on Pathogenesis}

Both mono limb and symmetrical two or four limbs ischemic necrosis have the same features of microthrombosis associated with a disturbed procoagulant-anticoagulant balance. ${ }^{[4]}$ There is an associated deep vein thrombosis (DVT) in mono limb ischemic necrosis, as seen in the complications of cancer-associated DIC or heparin-induced thrombocytopenia. However, DVT is not found in PF or SPG.

Most authors reported that SPG is a result and manifestation of DIC. ${ }^{[1,3,4]}$ This is based on the finding that in DIC, there is a reduction of antithrombin (AT) level, ${ }^{[35]}$ and at the same time, there is increase in the expression of plasminogen activator inhibitor- 1 which is mediated by endotoxin and tumor-necrosis-factor- $\alpha$. Consequently, the exaggerated coagulation together with impaired anticoagulant and

\begin{tabular}{ll}
\hline \multicolumn{2}{l}{ Table 1: Etiology of symmetrical peripheral gangrene } \\
\hline Infective & Noninfective \\
\hline Bacterial & Cardiovascular \\
Neisseria meningitidis & Myocardial infarction \\
Streptococcus pneumoniae & Cardiac failure \\
Staphylococcus aureus & Hypovolemic shock \\
Streptococcus pyogenes & Hypertension \\
Klebsiella pneumoniae & Pulmonary embolism \\
Salmonella paratyphi & Supraventricular tachycardia \\
Proteus vulgaris & Drugs \\
Proteus mirabilis & Adrenaline \\
Pasteurella multocida & Noradrenaline \\
Enterococcus faecalis & Dopamine \\
Escherichia coli & Warfarin \\
Mycobacterium & Propylthiouracil \\
tuberculosis & Malignancy \\
Capnocytophaga & Hodgkin's lymphoma \\
Parasitic & Lung adenocarcinoma \\
Plasmodium falciparum & Adenocarcinoma-associated \\
Viral & thrombotic endocarditis \\
Viral gastroenteritis & Connective tissue disorders \\
Rubeola & Systemic lupus erythematosus \\
Varicella zoster & Polymyalgia rheumatic \\
Dengue & Antiphospholipid syndrome \\
HIV & Miscellaneous \\
& Deficiency of Protein C and S \\
& Sickle cell disease \\
& Cryoglobulinemia \\
& Suprapubic prostatectomy \\
& Emergency neurosurgery \\
\hline IIV: Hopathic \\
\hline
\end{tabular}

HIV: Human immunodeficiency virus fibrinolysis system results in continuous thrombus formation, particularly in systemic small-sized and midsize vessels. This will eventually lead to multiorgan dysfunction ${ }^{[35]}$ and also SPG. ${ }^{[4]}$ Clinically, there are two types of DIC, i.e., one that develops slowly and causes thrombotic and/or embolic manifestations and one that develops rapidly and causes bleeding. ${ }^{[36]}$ SPG is the result of the second-type DIC.

SPG is also theorized to occur due to protein $\mathrm{C}$ deficiency and reduced pro-coagulant factor VII. In severe sepsis, there is increased protein $\mathrm{C}$ consumption, protein $\mathrm{S}$ inactivation, downregulation of cytokine-mediating signaling, and increased proteolytic enzymes release, which in turn favor microvascular thrombosis and increased leukocyte adhesion. ${ }^{[4,35]}$ Conditions that favor deficiency of protein $\mathrm{C}$ can be found in Shwartzman reaction due to meningococcal septicemia, ${ }^{[7,37]}$ while conditions that favor reduced procoagulant factor VII are seen in complicated cancer patients, heparin-induced thrombocytopenia, or warfarin therapy. ${ }^{[23,24]}$

The unique depletion of factor VII and protein C in DIC can partly be explained by their short half-lives, i.e., factor-VII $5 \mathrm{~h}$ and protein $\mathrm{C}-9 \mathrm{~h}$, compared to prothrombin factor $-60 \mathrm{~h} \cdot{ }^{[24]}$

\section{Pathology Findings}

Biopsy is the most reliable form of diagnosis for the pathology of SPG. Most SPG specimens show microthrombi in the capillary lumen of superficial and deep vascular plexus, accompanied by the deposition of fibrin and subtle extravasation of red blood cells.

Subepidermal cell-poor bulla may be found in biopsy specimen, but neither vasculitis nor inflammatory infiltrates are observed in the vascular walls. ${ }^{[9]}$ Edematous endothelial cells, capillary dilatation, and red cells extravasation contribute to petechial appearance of early lesions, which later will coalesce into the area of ischemic necrosis with associated bullae. ${ }^{[12]}$

This will first affect the dermal and subdermal tissues. When extensive peripheral necrosis develops, it can involve the underlying tissues and bone. ${ }^{[4]}$ Microangiopathic changes such as schistocytes should be sought on peripheral blood smear because it may indicate the presence of DIC. ${ }^{[9]}$ Postmortem studies on patients who died because of multiorgan failure show microthrombi in kidneys (cortical necrosis), lungs, liver, spleen, adrenal glands, heart, brain, pancreas, and gastrointestinal tract. ${ }^{[4]}$ Bilateral adrenal hemorrhage with evidence of fibrin microthrombi within the adrenal sinusoids is seen in adrenal failure due to meningococcal infection. This is also known as Waterhouse-Friderichsen syndrome. ${ }^{[38]}$

\section{Scope of Clinical Presentations}

Most patients with SPG have septicemia or in septic shock condition admitted to medical intensive care unit. At least $50 \%$ have underlying cancer together with DIC. ${ }^{[39]}$ Some cases have implicated hypotension requiring vasopressor therapy such as dopamine, noradrenaline, or 
phenylephrine. ${ }^{[4]}$ The affected limb appears pale or bluish discoloration, swollen, and painful (phlegmasia cerulea dolens) ${ }^{\left[{ }^{[3]}\right.}$ Bullae (often hemorrhagic) might develop over the acral region (distal part) of the limb, which indicates tissue necrosis. The dermal lesions are sharply demarcated and symmetric, with initial grayish blue or purple discoloration that will quickly turn to gangrenous. ${ }^{[7]}$ The distal pulses are still palpable even discolorations of distal fingers or toes have occurred ${ }^{[4,9]}$ Peripheral Doppler ultrasonography shows that large peripheral arteries are not involved in thrombosis. ${ }^{[10]}$ The ischemic necrosis will typically affect the lower limbs first before the upper limbs ${ }^{[4]}$ Bone scan can judge the extent of tissue injury. ${ }^{[40]} \mathrm{A}$ surge in serum lactate level as well as development of acrocyanosis may be indicative of impending SPG. ${ }^{[1]}$

Depending on the underlying conditions, mild splenomegaly can be palpated in falciparum malaria: ${ }^{[16]}$ otherwise, the rest of the physical examination is not specific. ${ }^{[2,4]}$ Laboratory shows similar results with DIC, i.e., thrombocytopenia, elevated fibrin D-dimer, and thrombin-AT complex. International normalized ratio typically exceeds 4.0. ${ }^{[4]}$ Specific test of protein C level is usually $<10 \%$ of normal. ${ }^{[35]} \mathrm{AT}$ level is also reduced due to rapid clearance from circulation after forming complex with thrombin or its degradation by elastases released from activated neutrophils. ${ }^{[35]}$ In patients with heparin-induced thrombocytopenia, the decrease in the platelet count usually begins 5-10 days after the immunizing exposure to heparin. ${ }^{[4]}$ Peripheral blood film may reveal schistocyte ${ }^{[4,9]}$ or certain parasite such as Plasmodium falciparum. ${ }^{[16]}$ Repeated screening of DIC is advocated because DIC may manifest in the later course of the disease. ${ }^{[10,12]}$ The summary of useful investigations is summarized in Table 2.

SPG should be differentiated with other causes of acral gangrene such as thromboangiitis obliterans, atherosclerosis, thromboembolic gangrene, secondary Raynaud's phenomenon, diabetes, neuropathy, chemical or toxic agents, calciphylaxis, and vasculitides. ${ }^{[1]}$ Meticulous analysis of history and natural cause, absence of vasculitides features, and sparing of major arteries, of which pulses can still be palpable, should be able to rule out SPG from other conditions. ${ }^{[9]}$

\section{Treatment Guideline}

There are minimal evidence-based guidelines for the treatment of SPG. However, it is a general consensus that the goal of treatment is to halt the progression of the disease, to remove the causative factors, to prevent secondary infections, to correct hypovolemia, and to remove nonviable tissue. Management should involve multidiscipline approach involving multiple caregivers, such as internist or critical care specialist, dermatologist, hematologist, and general or orthopedic surgeons. The patient should be admitted to critical care unit. Shock from blood extravasation and sepsis requires extensive fluid replacement. The source of infection or precipitating factors should be sought and treated. ${ }^{[1,2,4,10]}$ Care must be taken

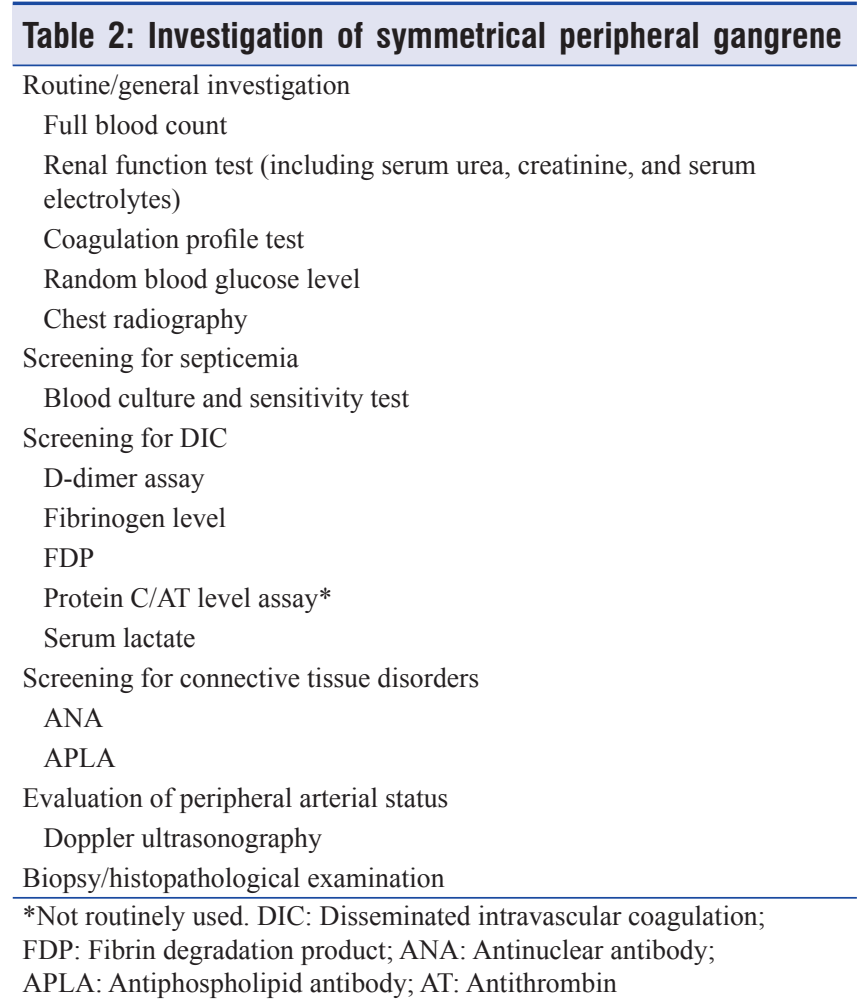

to use vasopressor agents in sepsis-induced hypotension as it might aggravate the condition. ${ }^{[30,31]}$

DIC should be sought and corrected promptly. Treatment guideline for DIC is quite established with emphasis on treating the underlying disease ${ }^{[41]}$ If bleeding is predominant, or those at high risk of bleeding requiring invasive procedures, depleted coagulation factors are replaced by the administration of platelet concentrate and fresh frozen plasma. ${ }^{[41]}$ In cases, where thrombosis is predominant, several anticoagulants are available. Low dose of unfractionated heparin (300-500 IU/hour) may be helpful to halt the progression of pregangrenous changes to frank gangrene. ${ }^{[1]}$ However, heparin usage has not been proven to improve the survival in patients with DIC. ${ }^{[10,41]}$ Low-molecular-weight heparin is found to be superior to unfractionated heparin. ${ }^{[41]}$ AT concentrate also does not significantly show to reduce mortality in DIC patients with severe sepsis. ${ }^{[42]}$ Based on the success of Protein C Worldwide Evaluation in Severe Sepsis trial, Food and Drug Administration in 2002 approved the usage of recombinant human activated protein $\mathrm{C}$ (rhAPC) for severe sepsis. ${ }^{[43]}$ However, subsequent randomized controlled trial (RCT) failed to show clinical benefits of rhAPC, and increased incidence of hemorrhage-related adverse events was noted. Thus, rhAPC had been withdrawn from treatment regimens of DIC with sepsis. ${ }^{[4]}$ Treatment with AT and recombinant human-soluble thrombomodulin is recommended in DIC patients with organs failure. ${ }^{[41]}$

Other medical treatments, such as trimethaphan, ${ }^{[9]}$ sodium nitroprusside, ${ }^{[31]}$ nitroglycerine ointment, ${ }^{[9]}$ intravenous alpha blocker (phentolamine and chlorpromazine), ${ }^{[10]}$ intravenous 
epoprostenol, and recombinant tissue plasminogen activator, ${ }^{[45]}$ have been reported in the literature; however, there have no proven clinical controlled trials. Other institution also combined with hyperbaric oxygen therapy. ${ }^{[4]}$ However, the use of inferior vena cava filters in patients with hypercoagulable states such as cancer or heparin-induced thrombocytopenia is not advisable because it predisposes to the development of venous gangrene. ${ }^{[14]}$ Papaverine, reserpine, dextran, and usage of plasmapheresis have been used in the treatment of SPG; however, none has proven beneficial. ${ }^{[9]}$

Limb vascular and compartment pressure should be monitored closely to enable early escharotomy and/or fasciotomy, when necessary. ${ }^{[27]}$ However, fasciotomy may disrupt the skin barrier and results in the interruption or delay of anticoagulant therapy. ${ }^{[4]}$ Bullae from the skin should be treated with topical antimicrobials (such as silver sulfadiazine) to prevent secondary infection. ${ }^{[27]}$ Debridement of nonviable or tissue should be carried out as soon as the patient's condition allows; however, early limb amputation should be avoided. Ample of time should be allowed to observe gangrene demarcation occurs because it can be difficult to distinguish viable and nonviable tissue clinically. ${ }^{[4]}$ The affected areas can be covered with skin graft. ${ }^{[9,27]}$ Patients, particularly those infected with meningococcal or pneumococcal, should be isolated for monitoring, and the health staffs should administer prophylactic antibiotics as well. ${ }^{[7,11]}$

\section{Prognosis}

SPG results in high rates of amputation and mortality. Multiple distal or acral amputations (i.e., fingers or toes) or more proximal amputations (i.e., above knee or elbow) are well-documented sequelae of this condition. ${ }^{[12]}$ Mortality in the acute phase is $18 \%-40 \%,{ }^{[21]}$ while other authors reported as high as $90 \%$. ${ }^{[2]}$

\section{Conclusion}

SPG is a rare, but devastating complication of sepsis. The treatment of SPG is largely anecdotal. ${ }^{[10]}$ Theoretically, the treatment of the SPG involves heparin-based anticoagulation and the substitution of natural anticoagulants. ${ }^{[4]}$ Early recognition of acrocyanosis, prompt management of DIC and underlying condition, hemodynamic stabilization, and properly controlled usage of anticoagulation may be helpful to halt the progression of pregangrenous stage to frank gangrene ${ }^{[1]}$ Since the rarity of SPG cases and of high mortality rate, multicenter RCT should be set up to formulate the proper treatment guidelines. The exact pathogenesis links to SPG are still under investigation. Hopefully, research in translational medicine will aid to clarify the pathways and the solution to disturbed procoagulant-anticoagulant balance that leads to SPG.

\section{Financial support and sponsorship}

Nil.

\section{Conflicts of interest}

There are no conflicts of interest.

\section{RefERENCES}

1. Sharma BD, Kabra SR, Gupta B. Symmetrical peripheral gangrene. Trop Doct 2004;34:2-4.

2. Chalmers E, Cooper P, Forman K, Grimley C, Khair K, Minford A, et al. Purpura fulminans: Recognition, diagnosis and management. Arch Dis Child 2011;96:1066-71.

3. Ghosh SK, Bandyopadhyay D, Dutta A. Purpura fulminans: A cutaneous marker of disseminated intravascular coagulation. West J Emerg Med 2009; 10:41.

4. Warkentin TE. Ischemic limb gangrene with pulses. N Engl J Med 2015;373:642-55.

5. Tuddenham EG, Takase T, Thomas AE, Awidi AS, Madanat FF, Abu Hajir MM, et al. Homozygous protein C deficiency with delayed onset of symptoms at 7 to 10 months. Thromb Res 1989;53:475-84.

6. Lerolle N, Carlotti A, Melican K, Aubey F, Pierrot M, Diehl JL, et al. Assessment of the interplay between blood and skin vascular abnormalities in adult purpura fulminans. Am J Respir Crit Care Med 2013;188:684-92.

7. Wong VK, Hitchcock W, Mason WH. Meningococcal infections in children: A review of 100 cases. Pediatr Infect Dis J 1989;8:224-7.

8. Manco-Johnson MJ, Abshire TC, Jacobson LJ, Marlar RA. Severe neonatal protein $\mathrm{C}$ deficiency: Prevalence and thrombotic risk. J Pediatr 1991;119:793-8.

9. Ghosh SK, Bandyopadhyay D. Symmetrical peripheral gangrene. Indian J Dermatol Venereol Leprol 2011;77:244-8.

10. Ghosh SK, Bandyopadhyay D, Ghosh A. Symmetrical peripheral gangrene: A prospective study of 14 consecutive cases in a tertiary-care hospital in Eastern India. J Eur Acad Dermatol Venereol 2010;24:214-8.

11. Johansen K, Hansen ST Jr. Symmetrical peripheral gangrene (purpura fulminans) complicating pneumococcal sepsis. Am J Surg 1993;165:642-5.

12. Davis MD, Dy KM, Nelson S. Presentation and outcome of purpura fulminans associated with peripheral gangrene in 12 patients at mayo clinic. J Am Acad Dermatol 2007;57:944-56.

13. Kashyap R, Behl RK, Mahajan S, Jaret P, Patial RK, Kaushal SS, et al. Symmetrical peripheral gangrene due to viral gastroenteritis. J Assoc Physicians India 2004;52:500-1.

14. Rice L. A clinician's perspective on heparin-induced thrombocytopenia: Paradoxes, myths and continuing challenges. In: Warkentin E, Greinacher A, editors. Heparin-Induced Thrombocytopenia. $5^{\text {th }}$ ed. Boca Raton, FL: CRC Press; 2013. p. 608-17.

15. Kullberg BJ, Westendorp RG, van 't Wout JW, Meinders AE. Purpura fulminans and symmetrical peripheral gangrene caused by Capnocytophaga canimorsus (formerly DF-2) septicemia - A complication of dog bite. Medicine (Baltimore) 1991;70:287-92.

16. Abdali N, Malik AM, Kamal A, Ahmad M. Symmetrical peripheral gangrene due to Plasmodium falciparum malaria. BMJ Case Rep 2014;2014. pii: bcr2014204268.

17. Patial T, Sharma K, Jaswal AS, Thakur V, Negi S. Symmetrical peripheral gangrene and tuberculosis: A rare kinship. Int J Mycobacteriol 2017;6:407-9.

18. McGouran RC, Emmerson GA. Symmetrical peripheral gangrene. $\mathrm{Br}$ Heart J 1977;39:569-72.

19. Neki NS, Jain A, Bajaj R, Jindal MM, Chavan V, Kumar H. Symmetrical peripheral gangrene: An unusual presentation of dengue fever. JK Sci 2015;17:104-5.

20. Roh SS, Gertner E. Digital necrosis in acquired immune deficiency syndrome vasculopathy treated with recombinant tissue plasminogen activator. J Rheumatol 1997;24:2258-61.

21. Vaiphei K, Vaidya PC, Vignesh P, Barwad P, Gupta A. Recurrent ventricular tachycardia and peripheral gangrene in a young child. Indian Pediatr 2016;53:815-21.

22. Molos MA, Hall JC. Symmetrical peripheral gangrene and disseminated intravascular coagulation. Arch Dermatol 1985;121:1057-61.

23. Klein L, Galvez A, Klein O, Chediak J. Warfarin-induced limb gangrene in the setting of lung adenocarcinoma. Am J Hematol 2004;76:176-9.

24. Warkentin TE, Whitlock RP, Teoh KH. Warfarin-associated multiple digital necrosis complicating heparin-induced thrombocytopenia and Raynaud's phenomenon after aortic valve replacement for 
adenocarcinoma-associated thrombotic endocarditis. Am J Hematol 2004; 75:56-62.

25. Diwan AG, Mittal J, Jadhay A, Pradhan AB. Symmetrical peripheral gangrene with multifactorial origin. J Indian Acad Geriatr 2005;3:103-9.

26. Yoo JH, Min JK, Kwon SS, Jeong CH, Shin WS. Symmetrical peripheral gangrene complicating Klebsiella pneumoniae sepsis associated with antiphospholipid antibodies. Ann Rheum Dis 2004;63:459-60.

27. Fagan S, Spies M, Hollyoak M, Muller MJ, Goodwin CW, Herndon DN. Exfoliative and necrotizing diseases of the skin. In: Herndon DN, editor. Total Burn Care. $3^{\text {rd }}$ ed. Edinburgh, London: Elsevier; 2007. p. 554-65.

28. Dalai SP, Meher LK, Behera SK, Nayak S, Tripathy SK. An unusual case of HCV negative cryoglobulinemia presenting as symmetrical peripheral gangrene. J Clin Diagn Res 2016;10:OD18-9.

29. Colak T, Erdogan O, Yerebakan O, Arici C, Gurkan A. Symmetrical peripheral gangrene and dopamine. Ulus Travma Acil Cerrahi Derg 2003;9:222-4

30. Hayes MA, Yau EH, Hinds CJ, Watson JD. Symmetrical peripheral gangrene: Association with noradrenaline administration. Intensive Care Med 1992;18:433-6.

31. Joynt G, Doedens L, Lipman J, Bothma P. High-dose adrenaline with low systemic vascular resistance and symmetrical peripheral gangrene. S Afr J Surg 1996;34:99-101.

32. Farah RE, Shay MD. Symmetrical peripheral gangrene and neutropenia following propylthiouracil. Ann Pharmacother 2006;40:1211.

33. Crisci A, Giannarini G, Selli C. Symmetrical peripheral gangrene after suprapubic prostatectomy. Scand J Urol Nephrol 2002;36:478-80.

34. Phan PN, Acharya V, Parikh D, Shad A. A rare case of symmetrical four limb gangrene following emergency neurosurgery. Int J Surg Case Rep $2015 ; 16: 15-8$

35. Ikezoe T. Thrombomodulin/activated protein $\mathrm{C}$ system in septic disseminated intravascular coagulation. J Intensive Care 2015;3:1

36. Moake JL. Disseminated Intravascular coagulation (DIC) (Consumption
Coagulopathy; Defibrination Syndrome). MSD Manual Professional Version. Available from: https//www.msdmanuals.com/professional/ hematology-and-oncology/coagulation-disorders/disseminatedintravascular-coagulation-dic/. [Last revision on $2018 \mathrm{Jul} 20$ ].

37. Meyers BR, Hirschman SZ, Sloan W. Generalized Shwartzman reaction in man after a dog bite. Consumption coagulopathy, symmetrical peripheral gangrene, and renal cortical necrosis. Ann Intern Med 1970;73:433-8.

38. Fox B. Disseminated intravascular coagulation and the Waterhouse-Friderichsen syndrome. Arch Dis Child 1971;46:680-5.

39. Perkins JM, Magee TR, Galland RB. Phlegmasia caerulea dolens and venous gangrene. Br J Surg 1996;83:19-23.

40. Hamdy RC, Babyn PS, Krajbich JI. Use of bone scan in management of patients with peripheral gangrene due to fulminant meningococcemia. J Pediatr Orthop 1993;13:447-51.

41. Wada H, Matsumoto T, Yamashita Y. Diagnosis and treatment of disseminated intravascular coagulation (DIC) according to four DIC guidelines. J Intensive Care 2014;2:15.

42. Warren BL, Eid A, Singer P, Pillay SS, Carl P, Novak I, et al. Caring for the critically ill patient. High-dose antithrombin III in severe sepsis: A randomized controlled trial. JAMA 2001;286:1869-78.

43. Bernard GR, Vincent JL, Laterre PF, LaRosa SP, Dhainaut JF, Lopez-Rodriguez A, et al. Efficacy and safety of recombinant human activated protein C for severe sepsis. N Engl J Med 2001;344:699-709.

44. Ranieri VM, Thompson BT, Barie PS, Dhainaut JF, Douglas IS, Finfer S, et al. Drotrecogin alfa (activated) in adults with septic shock. N Engl J Med 2012;366:2055-64.

45. Denning DW, Gilliland L, Hewlett A, Hughes LO, Reid CD. Peripheral symmetrical gangrene successfully treated with epoprostenol and tissue plasminogen activator. Lancet 1986;2:1401-2.

46. Stewart S. Symmetrical peripheral gangrene and the use of systemic hyperbaric oxygen therapy. J Wound Care 2012;21:615-6, 618-9. 